\title{
Corporate law, corporate governance and the pursuit of sustainability
}

\author{
Christopher M. Bruner and Beate SjåfJell
}

\section{Introduction}

This Handbook has sought to illuminate how corporate law and corporate governance affect the pursuit of corporate sustainability from a number of perspectives, drawing upon various disciplinary frameworks and employing a range of methodologies to analyze state-of-the-art developments in jurisdictions and markets around the world. While all of our contributors have naturally - and quite ably - provided their own assessments of the legal and regulatory landscapes described in their respective chapters, we take this final chapter as an opportunity to step back and assess the whole. In so doing, we draw upon specific examples from the foregoing chapters here and there, but we do so in a spirit of highlighting general trends and taking stock of the degree to which the innovations presented can be said to further the overarching aim of corporate sustainability. ${ }^{1}$

As a threshold matter, it bears reiterating that in speaking of "sustainability" as a goal, we use the term quite literally. In this strict sense, a practice can accurately be described as "sustainable" only if, at a minimum, it could be pursued indefinitely without further degradation of the environmental, social, and economic ecosystems on which we depend for our survival. ${ }^{2}$ This may strike the reader as rather a high bar to set - perhaps even unfairly so. Our response is that we can afford to pursue nothing less. As our introductory chapter details, we remain on a decidedly unsustainable path, having transgressed already several of the "planetary boundaries" hitherto identified by the scientific community as the effective limits of the environmental system upon which our survival depends. ${ }^{3} \mathrm{At}$ the same time, as several contributions to the Handbook also indicate, human rights abuses connected with transnational modes of corporate production remain widespread, and shareholdercentric corporate law and governance have widely come to be viewed as contributing to growing economic disparities - particularly in the wake of the global financial crisis. In this light, the grand challenge of our time straightforwardly becomes securing our social foundation, today and in the future, while remaining within our planetary boundaries. ${ }^{4}$ The framing of our inquiry is not so much a matter of editorial discretion as it is an acknowledgement of unavoidable facts about the world, our place within it, and our impact upon it.

As to the role of corporate law and corporate governance as such, we believe that their relevance to the achievement of corporate sustainability can no longer reasonably be contested. It has been vigorously maintained by influential scholars and policymakers that, to the degree achieving sustainability is a problem, it is most efficiently addressed through extra-corporate regulation (e.g. labor law, environmental law, etc.). ${ }^{5}$ However, the convergence of environmental, social, and economic crises motivating this Handbook speaks for itself. Incentivizing unbridled risk-taking and

\footnotetext{
${ }^{1}$ In some instances below, we refer generally to patterns and themes that arise consistently throughout the Handbook, foregoing voluminous cross-references. Specific cross-references are provided in other instances, however, where points more specific to particular chapters are addressed.

2 This is not to disregard the necessity of regeneration and remediation. See, in the environmental context, B.J. Richardson, Time and Environmental Law: Telling Nature's Time (Cambridge: Cambridge University Press, 2017).

${ }^{3}$ W. Steffen, K. Richardson, J. Rockström, S. E. Cornell, I. Fetzer, E. M. Bennett, R. Biggs, S. R. Carpenter, W. de Vries, C. A. de Wit, C. Folke, D. Gerten, J. Heinke, G. M. Mace, L. M. Persson, V. Ramanathan, B. Reyers and S. Sörlin, 'Planetary boundaries: Guiding human development on a changing planet' (2015) 347 Science 1259855.

${ }^{4} \mathrm{M}$. Leach, K. Raworth and J. Rockström, 'Between social and planetary boundaries: Navigating pathways in the safe and just space for humanity', in World Social Science Report 2013: Changing Global Environments (Paris: OECD Publishing, 2013), pp. 84-90.

${ }^{5}$ For a classic statement of this position, see F.H. Easterbrook and D.R. Fischel, The Economic Structure of Corporate Law (Cambridge, Mass.: Harvard University Press, 1991), pp. 35-39.
} 
substantial externalization of costs upon the environment and society, and then hoping that extracorporate regulation - typically ex-post and reactive in nature - can mitigate the resulting excesses, simply has not worked. Even those inclined toward the mainstream view have begun to concede that corporations powerful enough to write their own rules and conform such extra-corporate regulatory constraints to their own business imperatives undermine the core premise of the mainstream argument. ${ }^{6}$ The bodies of law and regulation that give rise to corporate entities, and condition their governance, cannot be bracketed in this manner if corporate sustainability is to be achieved. Corporate law and governance should, and indeed must, be conceptualized with sufficient breadth to address directly the grand challenge of our time in all of its interrelated dimensions environmental, social, and economic.

In this light, we posed from the outset a series of pressing questions about corporate law, corporate governance, and the sustainability of resulting modes of corporate production around the world that require close study. Specifically:

- How does the growing mismatch between global markets and territorially rooted national regulation affect the sustainability of corporate production and potential regulatory responses?

- How do shareholder-orientation generally, and widespread commitment to shareholder wealth maximization in particular, affect capacity to achieve corporate sustainability?

- How do trends in the organization of corporate firms, commercial markets, and financial systems affect capacity to achieve corporate sustainability?

- What innovations in corporate law and governance have these challenges prompted, and how effective can we expect them to be in achieving corporate sustainability?

- In light of the foregoing, where is further research required?

This Handbook has addressed these and related questions, marshaling analyses and insights from scholars around the world to shed light on what we know at this point; what sorts of initiatives have shown results, or fallen short, as the case may be; and where we ought to direct our efforts from here.

\section{Global Markets and National Regulation}

A significant background condition to contemporary debates about corporate sustainability is the growing geographic mismatch between regulators and regulated. As the contributions to Part I of the Handbook analyse directly - and as several other contributions further explore - commercial and financial markets have become increasingly global in nature, while regulation has remained territorially bound. To be sure, various initiatives aimed at coordinating regulators and substantive regulation at the international level have coalesced, and continue to develop, showing some promise as a means of constraining the ability of businesses to engage in regulatory arbitrage. The successes, however, have been quite limited relative to the scope of the commercial and financial activity increasingly pursued across national borders.

Tellingly, efforts to achieve international coordination have been most successful when they seek to foster cross-border commercial and financial activity - with noteworthy examples including international trade regimes and, to a lesser extent, international investment regimes. ${ }^{7}$ Meanwhile, efforts to coordinate cross-border regulatory constraints on such activity remain modest in scope, and/or aspirational in nature - consensus-based exercises under the auspices of the UN representing a vivid example. International enforcement mechanisms for corporate sustainability-oriented

\footnotetext{
${ }^{6}$ See e.g. J. Armour et al., 'Beyond the Anatomy', in R. Kraakman et al., The Anatomy of Corporate Law: A Comparative and Functional Approach (Oxford: Oxford University Press, 3d. ed. 2017), pp. 271-72; L.E. Strine, Jr. and N. Walter, 'Conservative Collision Course?: The Tension Between Conservative Corporate Law Theory and Citizens United' (2015) 100 Cornell Law Review 335-90 at 379-87.

${ }^{7}$ See C. Gammage and T. Novitz, 'Trade, investment and corporate sustainability', Ch. 2 in this volume.
} 
regulation remain patchy and unwieldy, and extraterritorial enforcement mechanisms pursued by domestic actors remain controversial, both legally and diplomatically. ${ }^{8}$

While initiatives aimed at curbing tax avoidance and outright evasion have garnered substantial attention and generated momentum among the world's major commercial and financial jurisdictions - because they implicate the public fisc in those very markets ${ }^{9}$ - other forms of regulatory competition receive less attention and continue to pose major challenges. Among other things, the mobility of capital and lack of coordination among regulators has placed downward pressure on prevailing regulatory standards relating to labor and the environment - in each case reducing production costs to the corporation by externalizing those costs - while reinforcing strong-form emphasis on generating profits as a commercial matter and maximizing shareholder wealth as a financial matter.

\section{Effects of Shareholder Wealth Maximization}

The lack of coordination among regulators and lawmakers described above has strongly reinforced shareholder primacy as a market norm. Corporate law has not mandated maximization of shareholder wealth, even among the most prominent commercial and financial jurisdictions. ${ }^{10}$ It is readily apparent from several analyses and jurisdictional case studies throughout this Handbook, however, that various relevant actors - including scholars, various forms of market participants, and policymakers alike - have increasingly taken for granted that shareholder interests are of primary significance as drivers of corporate decision-making. ${ }^{11}$ Other constituencies and interests, meanwhile, enter the picture solely as means to that end - the logical upshot of "enlightened shareholder value" policies. This increasing market emphasis on shareholders, and correlative disregard for other factors and impacts of corporate production, finds reinforcement in various areas of financial regulation - notably securities laws, stock exchange rules, and a proliferation of associated codes of best practice. These structures bring substantial shareholder-centric pressures to bear upon corporate governance, and may even generate a self-fulfilling prophecy over time as a matter of corporate law itself - to the degree that lawmakers and judges mistakenly interpret this market norm as a broadly held social norm, or otherwise come to view corporate law through a financialized policy lens.

This does not, of course, mean that those advocating greater sustainability have failed entirely to make inroads, or to establish the sustainability concept as part of the contemporary corporate governance lexicon. Indeed, the aim of this Handbook itself is to firmly establish sustainabilityoriented study of corporate law and governance as a field - an undertaking drawing inspiration from the range of efforts around the world analysed by our contributors. ${ }^{12}$ As discussed below, however, sustainability-oriented initiatives have (with limited exceptions) typically been hamstrung from the

\footnotetext{
${ }^{8}$ See K. Morrow and H. Cullen, 'De-fragmenting transnational business responsibility: principles and process', Ch. 4 this volume; J. Zhao, 'Extraterritorial attempts at addressing challenges to sustainability', Ch. 3 this volume.

${ }^{9}$ See J. Jaakkola and R. Knuutinen, 'The international order of corporate taxation: from market-building to sustainable fiscal settlement?', Ch. 9 in this volume.

${ }^{10}$ B. Sjåfjell, J. Mähönen, A. Johnston and Jay Cullen, 'Obstacles to Sustainable Global Business. Towards EU Policy Coherence for Sustainable Development' (March 18, 2019), University of Oslo Faculty of Law Research Paper No. 2019-02, available at https://ssrn.com/abstract=3354401; B. Sjåfjell, A. Johnston, L. Anker-Sørensen and D. Millon, 'Shareholder Primacy: The Main Barrier to Sustainable Companies', in B. Sjåfjell, B. J. Richardson (eds.), Company Law and Sustainability: Legal Barriers and Opportunities (Cambridge: Cambridge University Press, 2015), pp. 79-147; C. M. Bruner, Corporate Governance in the Common-Law World: The Political Foundations of Shareholder Power (Cambridge: Cambridge University Press, 2013).

${ }^{11}$ See particularly the analyses in Part II and the case studies in Part III. For an historical overview, see J.F. Sneirson, 'The history of shareholder primacy, from Adam Smith through the rise of financialism', Ch. 6 in this volume.

${ }^{12}$ See B. Sjåfjell and C.M. Bruner, 'Corporations and sustainability', Ch. 1 in this volume.
} 
beginning due to the perceived (if mistaken) necessity to conform them, both structurally and rhetorically, to the shareholder primacy norm. Due to the foregoing dynamics, reforms aimed at promoting corporate sustainability often gain traction only to the extent that a plausible "business case" can be made for them, blunting more ambitious initiatives and perhaps even leading would-be proponents not to propose them in the first place. In this manner, shareholder primacy sharply constrains our collective sense of the possible - even for many who favor pursuing corporate sustainability in the abstract. ${ }^{13}$

\section{Corporate Firms, Commercial Markets and Financial systems}

The foregoing dynamics associated with shareholder primacy are strongly reinforced by various developments in the structure of corporate firms, and various developments in commercial and financial markets, that greatly increase the complexity of corporate, commercial, and financial arrangements. The consequences are themselves numerous and complex, but for present purposes it suffices to observe that with complexity often comes opacity, impairing our ability to reckon the full costs of activity that becomes much more difficult to observe directly. Economies of scale and scope, and efficiencies of comparative advantage - which may, to be sure, provide real benefits - are weighed in the balance, while environmental and social costs - borne particularly by those residing outside the world's most affluent consumer and investment markets - are not.

Corporate group structures - utilized by multinational corporations ${ }^{14}$ - render it far more difficult for consumers and investors alike to discern how, by whom, and in what context a corporation's goods or services were produced. This, in turn, distances all of us from awareness of the production and associated risk-taking that we enable when we buy a company's products or stock. These dynamics are taken a step further, then, through global value chains, organized not through corporate parentsubsidiary relationships but through nominally arm's-length contracts in the global commercial marketplace among companies that may appear, at first glance, to have nothing to do with one another. ${ }^{15}$ Where pursued in this manner, modes of production become even more opaque to consumers and investors, distancing us from the consequences of our economic and financial decisions even more effectively than corporate group structures typically do.

On the investment side, however, this is only the beginning - because financial markets in many cases operate to insulate us from any awareness of the particular companies that our savings finance. These dynamics have been considerably augmented by the proliferation of financial professionals who have come to define today's highly intermediated financial markets - the portfolio managers and others who manage pooled investments funds, permitting those with limited resources to diversify their investments across a much larger range of companies and industries than a typical retail investor would ever consider. ${ }^{16}$ Most beneficial investors today would be hard pressed to name the companies in which their savings are invested, let alone to have any comprehension of those companies' production processes or their associated impacts.

Legal structures associated with these market structures only tend to reinforce the problematic practices and dynamics discussed above. The weakness of international regulatory coordination practically invites the use of corporate group structures and global value chains to pursue regulatory arbitrage strategies. The proliferation of financial intermediaries, meanwhile, displaces the potentially broader concerns that might inform an average consumer's or investor's evaluation of

\footnotetext{
${ }^{13}$ See C.M. Bruner, 'Conceptions of Corporate Purpose in Post-Crisis Financial Firms' (2013) 36 Seattle University Law Review 527-61 at 560-61.

${ }^{14}$ See B. Clarke and L. Anker-Sørensen, 'The EU as a potential norm creator for sustainable corporate groups', Ch. 14 in this volume.

${ }^{15}$ See J. Salminen, 'Sustainability and the move from corporate governance to governance through contract', Ch. 5 in this volume.

${ }^{16}$ See J. Cullen and J. Mähönen, 'Taming unsustainable finance: the perils of modern risk management', Ch. 8 in this volume.
} 
corporate practices with the myopia of a fiduciary who may be duty-bound (under investment management regulation) to maximize returns to beneficiaries.

\section{Innovations in Corporate Law and Governance}

In light of the foregoing contextual features and dynamics - the gulf between global markets and insufficiently coordinated national regulators, the persistent normative sway of shareholder primacy, and the distancing effects of corporate, commercial, and financial arrangements that render corporate production effectively opaque - it is hardly surprising that sustainability-oriented initiatives pursued to date have tended to assume the priority of investment returns. Indeed, in some cases, they have even tended to reinforce their priority.

Numerous analyses and jurisdictional case studies in the Handbook illustrate this overarching tendency. ${ }^{17}$ Benefit corporations represent a much-heralded form of social enterprise, and laudably aim to promote various social benefits toward which they may permissibly be directed through their organic documents - in which case the duties of the board and associated governance structures do deviate from the norm in discernible ways. Yet it is far from obvious that the benefits in fact outweigh the harms. The take-up of this form remains negligible, yet their very existence gives rise to the alarming (if unintentional) negative implication that non-benefit corporations - the vast majority in all such jurisdictions - need not concern themselves with any such matters; if a company wants to maraud the Earth, it need only decline to opt into the benefit corporation provisions of the given statute. ${ }^{18}$ As we have suggested, and take up further below, there is a far more pressing need to reform mainstream corporate law and governance for all companies, not just a self-selected few yet, at least among the world's major commercial and financial jurisdictions, efforts to this effect have been tentative at best. ${ }^{19}$

Similar efforts to reorient corporate governance have been undertaken on the investor side, notably through investment structures that formally incorporate sustainability-oriented considerations into investment decision-making. Green bonds represent a concrete example of what has been more broadly termed socially responsible investing (SRI). ${ }^{20}$ Such initiatives in the investment context are perhaps more promising in that they do not straightforwardly give rise to the sort of alarming negative implication that benefit corporations do. Yet greenwashing remains a problem, as do ambiguities regarding the goals and realistic expectations that retail investors might bring to investment in such instruments or funds. To the extent that such investment structures rely on (contestable) claims regarding how their returns measure up relative to non-SRI structures, they indirectly cultivate maximization of investment returns as a coherent metric for the desirability of these investments - as opposed to their intrinsic sustainability. In this light, the EU's Sustainable Finance Initiative - which offers some hope of bringing sustainability concerns directly to bear upon business and finance - represents a welcome development that several contributors rightly highlight. ${ }^{21}$

Other sustainability-oriented initiatives, meanwhile, hold current governance structures constant, aiming to leverage external market pressures upon companies to change their production practices. Certification, due diligence requirements, and environmental, social and governance (ESG)

\footnotetext{
${ }^{17}$ See particularly the case studies in Part III and the analyses in Part IV.

${ }^{18}$ See C. Liao, 'Social enterprise law: friend or foe to corporate sustainability?', Ch. 46 in this volume.

${ }^{19}$ Currently, there is some hope concerning the follow-up of the EU's Sustainable Finance Initiative, which has opened up a discussion on reforming the duties of the corporate board. See Action 10 of the European Commission, Action Plan: Financing Sustainable Growth, $\operatorname{COM(2018)~} 97$ final, 8.3.2018; B. Sjåfjell, 'Realising the potential of the board for corporate sustainability', Ch. 49 in this volume.

${ }^{20}$ See S.K. Park, 'Green bonds and beyond: debt financing as a sustainability driver', Ch. 42 in this volume.

${ }^{21}$ European Commission, Action Plan: Financing Sustainable Growth, COM(2018) 97 final, 8.3.2018. For critical reflections concerning this initiative, however, see Ch. 8.
} 
disclosures ${ }^{22}$ all similarly aim to bring the realities of far-flung corporate production processes and associated impacts to the attention of consumers, public procurement officials and retail investors who, it is hoped, will favor "good" companies over "bad" ones. Yet, such initiatives are plagued by greenwashing and a magnetic draw toward generic boilerplate. And even if such modes of information production could be improved substantively, it is unlikely that they could substantially overcome the distancing effects of the corporate, commercial, and financial market structures discussed above. Meanwhile, certain of these structures affirmatively reinforce shareholder primacy thinking, and accordingly narrow their own reach, by justifying themselves in terms of a financial analogue to the "business case" rationale. Notably, ESG disclosures are often presented as a reflection of (and cabined by reference to) the need for investors to assess these considerations as a distinctive basket of investment risks, without direct regard for the broader significance and impacts of the corporate production practices at issue.

Perhaps the least ambitious of all would be stewardship codes. While these codes of conduct for institutional investors may reflect some limited degree of societal push-back against the financial sector's general disengagement from broader environmental, social, and economic interests, ${ }^{23}$ they essentially hold constant all of the dynamics and governance-related problems discussed above. Ultimately they amount to little more than an expression of hope that institutions themselves contrary to their narrow interests and normative expressions of the primacy of investor returns - will nevertheless decide to favor sustainable corporate practices. Typically, the explanation closely resembles the rationale for ESG disclosures - i.e. attention to sustainability-related risks - and accordingly shares the shortcomings of that rationale.

\section{Further Research}

The foregoing discussion paints a rather bleak picture of well-intentioned yet insubstantial initiatives nibbling at the edges of large-scale fundamental problems. This, we fear, is the unfortunate reality of most contemporary initiatives that aim to promote corporate sustainability - they accomplish little because they hold constant the fundamental corporate governance structures that incentivize unbridled risk-taking and substantial externalization of costs upon society and the environment. At the same time, however, the shortcomings of such initiatives help reveal future directions for research - as do some of the more ambitious initiatives that depart from this trend.

It is not our intention to suggest that such initiatives contribute nothing, or that they cannot be improved on their own terms. For example, it remains entirely plausible that disclosure requirements and related initiatives could be reformed in ways that allow them to more effectively leverage consumer and investment market pressures in favor of sustainability. Throughout this Handbook, our contributors have sought to identify the strengths and shortcomings of a wide range of sustainability-oriented initiatives - as well as fruitful avenues for further related research - and on those matters we leave the reader in our contributors' hands. Nevertheless, existing initiatives plainly are not enough. The very fact that the successes of existing initiatives have been so limited tends to point toward an unpleasant underlying reality - we fail because we are holding constant the fundamentally problematic aspects of our current system. Prevailing approaches to corporate law and governance have incentivized the risk-taking and externalization of costs analyzed throughout this Handbook, and it is simply unrealistic to expect that these problems could be resolved without fundamental reforms to the corporate legal structures and governance systems giving rise to them.

\footnotetext{
${ }^{22}$ See e.g. I. Chiu, 'Disclosure regulation and sustainability: legalisation and governance implications', Ch. 37 in this volume; F. Möslein, 'Certifying "good" companies: a comparative study of regulatory design', Ch. 47 in this volume; C. Villiers, 'Global supply chains and sustainability: the role of disclosure and due diligence regulation', Ch. 39 in this volume.

${ }^{23}$ See D. Katelouzou, 'Shareholder stewardship: a case of (re)embedding institutional investors and the corporation?', Ch. 41 in this volume.
} 
In this light, it is worth emphasizing the handful of cases where more fundamental structural reforms - or alternative structures entirely - have been pursued. France, for example, has experimented with a more robust and enforceable duty for companies and their managers to prevent abuses in their corporate groups and supply chains worldwide. ${ }^{24}$ South Africa has implemented changes to the core governance structure itself, introducing a potentially powerful "Social and Ethics Committee," which arguably possesses far-reaching, original board powers relating to a range of sustainabilityoriented matters. ${ }^{25}$ Several jurisdictions, meanwhile, have facilitated pursuit of large-scale businesses through entirely different forms driven by different sets of fundamental aims - notably cooperatives, which seek to encode concern for the community within their governance structures as a central preoccupation. ${ }^{26}$

It is not our aim to endorse the pursuit of such models, either generally or as applied by any particular jurisdiction. For present purposes, the point is rather to observe the capacity for more fundamental reforms that they tentatively illustrate. Moving forward, it will be critical for further research to evaluate the efficacy of these particular corporate governance structures; to illuminate how and why they took shape, as a matter of political economy; and, just as importantly, to explore what their successes and failures ultimately reveal, by contrast, about mainstream corporate governance structures. In so doing, it will be critical that research in this area measure the degree to which sustainability-related initiatives actually contribute to meeting the grand challenge of our time - and not merely to a "business case" that is too often content with incremental improvements not in fact bringing about sustainable corporate practices.

The burgeoning field of corporate law, corporate governance and sustainability represents a critically important terrain for scholarly inquiry and public attention around the world. Today, pressing questions far outnumber compelling answers. It is our hope that this Handbook will advance scholarship in the area, inform policymakers, and contribute toward the development of models that can truly sustain the environmental, social, and economic ecosystems on which we all depend.

\footnotetext{
${ }^{24}$ See V. Magnier, 'Old-fashioned yet innovative: corporate law, corporate governance and sustainability in France', Ch. 20 in this volume.

${ }^{25}$ See T.H. Mongalo, 'The Social and Ethics Committee: innovating corporate governance in South Africa', Ch. 26 in this volume.

${ }^{26}$ See V. Pönkä, 'The cooperative as a platform for sustainable business operations', Ch. 48 in this volume.
} 